\title{
Association of histologically proven rheumatoid arthritis with pulmonary sarcoidosis
}

\author{
O. Menard*, N. Petit*, P. Gillet**, A. Gaucher**, Y. Martinet*+
}

Association of histologically proven rheumatoid arthritis with pulmonary sarcoidosis. $O$. Menard, N. Petit, P. Gillet, A. Gaucher, Y. Martinet. (CERS Journals Ltd 1995.

ABSTRACT: The association of rheumatoid arthritis proven by means of synovial biopsy with pulmonary sarcoidosis proven by means of bronchial biopsy, occurred in a 58 year old woman.

Corticosteroid therapy resulted in complete resolution of sarcoidosis but only slight improvement of the rheumatoid arthritis, which was secondarily treated with methotrexate with a successful outcome. Only two similar cases have been reported with simultaneous histological proofs of both diseases.

Eur Respir J., 1995, 8, 472-473.
*Clinique Pneumologique Médico-Chirurgicale, and **Service de Rhumatologie A, Hôpital de Brabois, Vandoeuvre-les-Nancy, France. + INSERM U14, Vandoeuvre-lesNancy, France.

Correspondence: O. Menard, Clinique Pneumologique Médico-Chirurgicale, $\mathrm{CHU}$ Nancy, 54511 Vandoeuvre-les-Nancy, France

Keywords: Interstitial lung diseases, pulmonary sarcoidosis, rheumatoid arthritis

Received: April 251994

Accepted after revision October 261994
Pulmonary involvement is common in rheumatoid arthritis, and includes pleural effusion, pulmonary intraparenchymal rheumatoid nodules, bronchiolitis and/ or interstitial lung disease with restrictive ventilatory impairment. Furthermore, treatment of rheumatoid arthritis with gold salts, D-penicillamine or methotrexate can induce iatrogenic pulmonary interstitial diseases [1]. On the other hand, osteoarticular involvement by sarcoidosis is rare, but can mimic rheumatoid arthritis disease in some acute or chronic polyarthritic forms [2]. Differential diagnosis is sometimes difficult when both pulmonary and osteoarticular manifestations are present. The association of rheumatoid arthritis or sarcoidosis with other connective tissue diseases or vasculitis is relatively rare, but has been described. For an unknown reason, the association of rheumatoid arthritis with sarcoidosis seems to be exceptional, and histological proof has been obtained in only two previous cases of lung sarcoidosis associated with RA, by simultaneous articular and pulmonary positive biopsies [3, 4]. We report a further case with histological proof of both diseases, and with a dissociated clinical course between the two diseases under treatment.

\section{Case report}

A 58 year old Caucasian woman was admitted, on March 16, 1989 following a 3 month history of polyarthralgia with symmetrical inflammatory polysynovitis of the proximal interphalangeal, metacarpophalangeal, wrist, ankle and knee joints. She also complained of progressive dyspnoea on exertion. Clinical examination confirmed inflammatory arthritis of the joints involved, predomi- nantly of the fingers. Pulmonary auscultation was normal. Knee and hand radiographic examination revealed moderate demineralization. Chest roentgenogram and computed tomography (CT) showed a diffuse bilateral reticulonodular interstitial pattern with mediastinal lymph node enlargement. Pulmonary function tests demonstrated moderate hypoxaemia (arterial oxygen tension $\left(\mathrm{PaO}_{2}\right) 10.3$ $\mathrm{kPa}(77.5 \mathrm{mmHg})$ and hypocapnia (arterial carbon dioxide tension $\left.\left(\mathrm{PaCO}_{2}\right) 4.7 \mathrm{kPa}(35 \mathrm{mmHg})\right)$ with normal lung volumes and flows but diminished carbon monoxide transfer factor $\left(17.94 \mathrm{ml} \cdot \mathrm{mmHg}^{-1} \cdot \mathrm{min}^{-1} ; 72 \%\right.$ of predicted).

A moderate bronchial inflammation was observed on fibreoptic bronchoscopy, and bronchial biopsies showed noncaseating epithelioid and giant cell granulomas. Cultures and specific stains for fungal and acid-fast microorganisms were negative. Bronchoalveolar lavage (BAL) analysis demonstrated a moderate hypercellularity $(472,000$ cells $\left.\cdot \mathrm{mm}^{-3}\right)$, and a marked elevation of the lymphocyte count $(56 \%)$, with a CD4/CD8 ratio of 2.5.

Laboratory data showed: an elevated erythrocyte sedimentation rate $\left(28 / 68 \mathrm{~mm} \cdot \mathrm{h}^{-1}\right.$ in first and second hour, respectively), a positive rheumatoid factor test, positive antinuclear antibodies (1/256), and normal serum lysozyme and angiotensin converting enzyme levels. Human leucocyte antigen (HLA) phenotype was $\mathrm{A}_{2} \mathrm{~A}_{3} \mathrm{~B}_{35} \mathrm{Cw}_{4} \mathrm{DR}_{5}$ $\mathrm{DR}_{6}$.

Due to lung functional impairment and to severe polyarthritis, corticosteroid therapy (prednisolone $0.5 \mathrm{mg} \cdot \mathrm{kg}^{-1}$ daily) was initiated, resulting in rapid improvement of both articular and pulmonary clinical symptoms. Six months later, chest roentgenogram and CT scan, pulmonary function tests and BAL revealed a complete resolution of pulmonary sarcoidosis. Clinical remission of 
osteoarticular signs was also observed. However, two months later the patient was readmitted following a new episode of acute polysynovitis, predominant on both wrists and fingers. After a complete clinical and radiological examination, a combination of corticosteroid (prednisolone $1 \mathrm{mg} \cdot \mathrm{kg}^{-1}$ daily) and methotrexate $\left(7.5 \mathrm{mg} \cdot \mathrm{week}^{-1}\right)$ therapy was initiated, achieving a dramatic improvement of rheumatological symptoms within 3 weeks. Fourteen months after initial admission, due to second and third metacarpophalangeal joint synovitis with associated retraction of the palmar aponeurosis, surgical palmar aponeurectomy and synovectomy of the second and third left metarcarpophalangeal joints were performed. Histological examination of the synovial biopsy specimen confirmed the presence of typical rheumatoid synovitis, with hyperplasia of synovial fringes, hyperplasia of synoviocytes, nodular perivascular lymphocytic and plasmocytic inflammation, neoangiogenesis and moderate fibrinoid necrosis.

The patient was followed-up with regular clinical examination, chest radiographs and pulmonary function tests. Four years after onset of symptoms, chest radiographs, chest CT scans and pulmonary function tests were normal. Osteoarticular status was assessed as being stable. Methotrexate $\left(7.5 \mathrm{mg} \cdot \mathrm{week}^{-1}\right)$ and low dose corti-

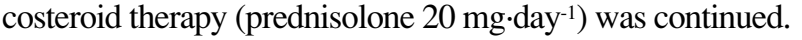

\section{Discussion}

We report a case of rheumatoid arthritis associated with pulmonary sarcoidosis in a female patient. Of particular interest is the dissociated clinical course of both diseases (resolution of pulmonary sarcoidosis, secondary progression of rheumatoid arthritis) under corticosteroid therapy.

A review of the literature disclosed only 10 previously reported cases of sarcoidosis associated with rheumatoid arthritis [3-9]. Of these 10 patients: eight had abnormal chest roentgenograms and/or CT; 10 had histological proof of sarcoidosis, but only four in the thorax (three on transbronchial biopsies and one on mediastinal lymph node biopsy); six had histological proof of rheumatoid arthritis (three on synovial biopsies and three on subcutaneous nodule biopsies); and no patient had histological proof of osteoarticular sarcoidosis. Finally, only two published cases have been reported with simultaneous histological proof of rheumatoid arthritis and pulmonary sarcoidosis [3, 4].

In the case reported by KUCERA [4] there was histological evidence of Sjögren's syndrome on lip biopsy.

Sarcoidosis and rheumatoid arthritis are relatively common diseases, but for unknown reasons, their association seems to be rare. The main pulmonary manifestations of rheumatoid arthritis include pleurisy, with or without effusion, intraparenchymal necrobiotic nodules, Caplan's syndrome, diffuse interstitial pneumonitis with or without fibrosis, obliterative bronchiolitis, pulmonary arteritis and/or hypertension [10]. Musculoskeletal manifestations of sarcoidosis include sarcoid myopathy, osseous osteolytic lesions usually located in hands and feet bones, acute or chronic polyarthritis, usually symmetrical, located on knees, elbows, ankles, wrists and hands, and rarely on sacroiliac joints [11-13].

In our case, the dissociated clinical course of the pulmonary and rheumatological manifestations raises the question of either a fortuitous association, or a nosologically related association of the two diseases, with dissociated response to treatment due to different pathophysiological mechanisms and corticosteroid therapy responsiveness. In daily practice, formal diagnosis may be difficult when pulmonary radiological and/or functional abnormalities are encountered in association with osteoarticular manifestations. Although bronchial or transbronchial biopsies through a flexible bronchoscope represent a low invasive and successful technique for the diagnosis of sarcoidosis, osteoarticular biopsies for rheumatoid arthritis diagnosis are much more invasive, explaining the low rate of histological synovial proofs of rheumatoid arthritis in the reported cases. Furthermore, disabling rheumatoid arthritis usually needs as first stage treatment strategy, the initiation of corticosteroid therapy, without the need of articular histological proof.

Acknowledgements: The authors thank M. Gény for preparation of the manuscript.

\section{References}

1. Prakash UBS. Rheumatological diseases. In: Murray JF, ed. Pulmonary Complications of Systemic Diseases. New York, Marcel Dekker 1992; pp. 384-393.

2. James G, Neville E, Carstair LS. Bone and joint sarcoidosis. Semin Arthritis Rheum 1976; 6: 53-81.

3. Fallahi S, Collins RD, Miller RK, Halla JT. Co-existence of rheumatoid arthritis and sarcoidosis: difficulties encountered in the differential diagnosis of common manifestations. J Rheum 1984; 11: 526-529.

4. Kucera MRF. A possible association of rheumatoid arthritis and sarcoidosis. Chest 1989; 95: 604-606.

5. Davis MW, Crotty RQ. Sarcoidosis associated with polyarthritis. Ann Intern Med 1952; 36: 1098-1106.

6. Putkonen T, Virkkunen M, Wager O. Joint involvement in sarcoidosis with special reference to the co-existence of sarcoidosis and rheumatoid arthritis. Acta Rheum Scand 1965; 11: 53-61.

7. Hillerdal O, Hultquist G, Linder L. A case of sarcoidosis, syphilis and rheumatoid arthritis: an unusual combination of systemic diseases. Acta Tuberc Scand 1965; 46: 65-70.

8. Thompson WR, Ferenzi GW. Sarcoidosis and rheumatoid arthritis. Ill Med J 1966; 129: 239-242.

9. Tane N, Hayashi M, Sakoda A, Mayeda A, Uda H. Extraarticular sarcoid lesions in a case treated as rheumatoid arthritis: a case report. Ryumachi 1980; 20: 358-367.

10. Hunninghake GW, Fauci AS. Pulmonary involvement in the collagen vascular diseases. Am Rev Respir Dis 1979; 119: 471-503.

11. Sartoris DJ, Resnick D, Resnick C, Yaghmai I. Musculoskeletal manifestations of sarcoidosis. Semin Roentgenol 1985; 20: 376-386.

12. Mijiyawa M, Fereres M, Deutsch JP, Awada H, Dongado M, Amor B. Atteinte pelvirachidienne de la sarcoïdose. Rev Rhum 1989; 56: 529-532.

13. Kirkham B, Joban Putra P. Sarcoidosis and spondylarthritis. Br J Rheum 1988; 27: 241-248. 